\title{
INHIBITIVE EFFECT OF DATE EXTRACT ON THE CORROSION OF CARBON STEEL IN ACIDIC MEDIA
}

\author{
NAIMA MOUSSAOUI*, DJILALI ZEROUALI AND NOUREDDINE BETTAHAR \\ Laboratory of Inorganic Materials Chemistry and Application; \\ Faculty of Chemistry, University of Science and Technology Mohamed-Boudiaf, PB.1505 EL-Menouar - ORAN 31000. Algeria
}

\begin{abstract}
The inhibitive effect of date extract on the corrosion of Carbon steel in $1 \mathrm{M} \mathrm{HCl}$ solution has been investigated by weight loss measurement, potentiodynamic polarization and electrochemical impedance spectroscopy (EIS) techniques. The presence of this extract reduces remarkably the corrosion rate of mild steel in acidic solution. The inhibition efficiency was found to increase with increasing inhibitor concentrations due to the adsorption of the inhibitor molecules on the metal surface, this adsorption follows Langmuir's adsorption isotherm. The inhibition efficiency was found to be $85.84 \%$ at $1.5 \mathrm{~V} / \mathrm{V} \% \mathrm{in} 1 \mathrm{M} \mathrm{HCl}$.

Temperature studies revealed a decrease in efficiency with rise in temperature.
\end{abstract}

Keywords: Carbon steel; Green corrosion inhibitors; Date extract; Electrochemical methods; Acid medium

\section{INTRODUCTION}

Acidic media are widely used in industries, with important fields of application including acid pickling of iron and steel, chemical cleaning and processing, ore production and oil well acidification. Among acidic media, the hydrochloric acid used in the pickling of metals, the acidification of oil wells and the cleaning of scales are more economical, efficient and straightforward compared to other mineral acids. ${ }^{1}$

The use of inhibitors is one of the most practical methods for steel protection against corrosion and prevention of unexpected metal dissolution and acid consumption, especially in acid solutions.

A number of organic compounds have been reported as effective corrosion inhibitors ${ }^{2-4}$. But, most of them are highly toxic to both human being and environment. Currently, research in corrosion is oriented to the development of "green corrosion inhibitors", compounds with good inhibition efficiency but low risk of environmental pollution ${ }^{5-6}$. Plant extracts are viewed as an incredibly rich source of naturally synthesized chemical compounds that can be extracted by simple procedures with low cost and are biodegradable in the environment.

Recently, several studies have been carried out on the inhibition of corrosion of metals by plant extract, Eugenol and Acetyleugenol ${ }^{7}$, Hibiscus subdariffa ${ }^{8}$, Azadirachta ${ }^{9}$, Vernonia amygdalina ${ }^{10}$, henna ${ }^{11}$, Nypa fruticans Wurmb ${ }^{12}$, Azadirachta indica ${ }^{13}$, Acalypha indica ${ }^{14}$, Zenthoxylum alatum ${ }^{15}$, Damsissa ${ }^{16}$, Phyllanthus amarus ${ }^{17}$, Murraya koenigii ${ }^{18}$, Justicia gendarussa ${ }^{19}$, Oxandra asbeckii ${ }^{20}$, ginkgo ${ }^{21}$, Stevia rebaudiana ${ }^{22}$, juice of Prunus cerasus ${ }^{23}$, Jojoba ${ }^{24}$, Salvia aucheri mesatlantica ${ }^{25}$, blak pepper ${ }^{26}$, Artemisia pallens ${ }^{27}$, Mentha rotundifolia leaves ${ }^{28}$, fruit peel ${ }^{29}$ and Natural honey ${ }^{30}$, have been found to be very efficient corrosion inhibitors.

The aim of this study is to investigate the inhibition effect of date extract as a cheap, raw and non-toxic corrosion inhibitor on steel corrosion in hydrochloric acid. The electrochemical measurements were carried out to evaluate the inhibiting efficiency. In addition, the effect of the temperature on inhibition behaviour of the inhibitor was also studied.

\section{EXPERIMENTAL}

\section{Preparation of date extract}

The dates are collected from the palm groves of Biskra region (south Algeria), are first washed in distilled water under room temperature, then immersed in boiling distilled water during 100 minutes under mechanical agitation.

The weight ratio dates/water is $1 \mathrm{~kg} / 4 \mathrm{~kg}$, at the end of this process; juice was separated by filtration under pressure. The recovered extract has a light brown colour and a volume of about 1,5litres.

The experimental solution was concentrated by evaporation of water excess for 1 hour. The final extract volume is 0.51 of a viscous, dark brown coloured product.
The concentrations used are: $0.05,0.1,0.4,0.7,1,1.2$ and $1.5 \mathrm{~V} / \mathrm{V} \%$

\section{Samples}

Working electrodes were prepared from carbon steel specimens with a w \% composition: $(0.159 \% \mathrm{C} ; 0.0173 \%$ If; $0.376 \% \mathrm{Mn} ; 0.00305 \% \mathrm{P} ; 0.0791 \%$ $\mathrm{Al} ; 0.00607 \% \mathrm{Cr} ; 0.0073 \% \mathrm{~S} ; 0.0165 \% \mathrm{Cu} ; 0.00151 \% \mathrm{Ti} ; 0.00475 \% \mathrm{~V}$; $0.0011 \% \mathrm{Sn}, 0.00198 \% \mathrm{Ni}$ and $99.33 \% \mathrm{Fe}$ ).

Samples were polished using different emery paper with 120 up to 1000 grade degreased with acetone, rinsed with double-distilled water then dried at room temperature.

The areas of working electrodes were $1 \mathrm{~cm}^{2}$ for all electrochemical experiments.

Solution $1 \mathrm{M} \mathrm{HCl}$ was used for all experiments.

\section{Weight loss measurements}

Carbon steel samples of dimensions $1 \mathrm{~cm} \mathrm{x} 1 \mathrm{~cm} \times 0.1 \mathrm{~cm}$, were prepared and cleaned as described elsewhere and immersed in the experimental solutions with and without date extract. Time duration of experiments were optimized and conducted for 24 hours at $20^{\circ} \mathrm{C}$.

The inhibition efficiency was obtained using the Eq (1):

$$
E(\%)=\frac{V-V_{i n h}}{V} \times 100
$$

Where $V$ and $V_{i n h}$ are the values of corrosion rate without and with inhibitor, respectively.

The corrosion rate $(V)$ is calculated by the following Eq (2):

$$
V=\frac{\Delta m}{S . t} \quad\left(\mathrm{mg} / \mathrm{cm}^{2} \cdot \mathrm{h}\right)
$$

Where $\Delta m$ is the average weight loss (mg), $S$ the specimen area $\left(\mathrm{cm}^{2}\right)$, and $t$ is immersion time (h).

\section{Electrochemical measurements}

\section{Open circuit potential measurement}

The open-circuit potentials (OCP) were recorded as a function of time, 50 minutes corresponding to the stabilization of the system.

\section{Potentiodynamic polarization measurements}

The dynamic polarizations were conducted in a potentiostat/galvanostat 
EG\&G 273A type. A three electrodes arrangement was used for electrochemical studies: a platinum electrode as a counter-electrode, a saturated calomel electrode (SCE) as a reference electrode and carbon steel as working electrode.

All the experiments were performed at $20^{\circ} \mathrm{C}$.

Potentiodynamic polarization curves were plotted at a polarization scan rate of $0.5 \mathrm{mV} / \mathrm{s}$. Before all experiments, the potential was stabilized at free potential during $50 \mathrm{~min}$.

The inhibition efficiency was calculated using Eq (3):

$$
E(\%)=\frac{\left(I_{\text {corr }}-I_{\text {corr }(i n h)}\right)}{I_{\text {corr }}} \times 100
$$

Where $I_{\text {corr }}$ and $I_{\text {(corr inh) }}\left(\mu \mathrm{A} / \mathrm{cm}^{2}\right)$ are respectively a corrosion current density in the absence and in the presence of inhibitor.

\section{Electrochemical impedance measurements}

Electrochemical impedance spectroscopy (EIS) measurements were carried out using ac signals of amplitude $5 \mathrm{mV}$ peak to peak in the frequency range of $100 \mathrm{kHz}$ to $20 \mathrm{mHz}$ for $50 \mathrm{~min}$ open circuit potential.

The Nyquist representation showed the results.

The charge transfer resistance values $\left(R_{c t}\right)$ were calculated from the difference in impedance at lower and higher frequencies. To obtain the doublelayer capacitance $\left(C_{d l}\right)$, the frequency relative to the maximum imaginary component of the impedance $\left(-Z_{i m a x}\right)$ is found out, and $C_{d l}$ values were obtained from the $\mathrm{Eq}(4)$ :

$$
f\left(-Z^{\prime \prime}{ }_{\max }\right)=\frac{1}{2 \pi C_{d l} R_{t}}
$$

The inhibition efficiency was calculated, using Eq (5):

$$
E(\%)=\frac{R_{c t}-R_{c t, 0}}{R_{c t}} \times 100
$$

Where $R_{c t, 0}$ and $R_{c t}\left(\Omega . \mathrm{cm}^{2}\right)$ respectively represent the values of the charge transfer resistance in absence and in the presence of the inhibitor.

\section{Surface Examination Studies}

Surface examination of carbon steel specimens in the absence and presence of the optimum concentration of the extract immersed for $24 \mathrm{~h}$ at $20^{\circ} \mathrm{C}$ was studied using JEOL JSM- 6100 Scanning electron microscope (SEM) with the magnification of $1000 x$ specimens.

\section{RESULTS AND DISCUSSIONS}

\section{Weight loss measurements}

Table1 gives the results of weight loss measurements in the absence and presence of different concentrations of extract.

Table 1. Corrosion rate and inhibition efficiency for different concentrations of date extract $\left(\mathrm{t}=20^{\circ} \mathrm{C}\right)$

\begin{tabular}{|c|c|c|}
\hline $\begin{array}{c}\text { Concentrations of date } \\
\text { extract }(\mathrm{V} / \mathrm{V} \%)\end{array}$ & $\begin{array}{c}\text { Corrosion rate } \\
\left(\mathrm{mg}^{-\mathrm{cm}^{-2}} \cdot \mathrm{h}^{-1}\right)\end{array}$ & $E(\%)$ \\
\hline blank & 0.4939 & 0 \\
\hline 0.05 & 0.2223 & 54.97 \\
\hline 0.1 & 0.2106 & 57.34 \\
\hline 0.4 & 0.1804 & 63.60 \\
\hline 0.7 & 0.1331 & 73.05 \\
\hline 1 & 0.1170 & 76.31 \\
\hline 1.2 & 0.1126 & 77.20 \\
\hline 1.5 & 0.1083 & 78.07 \\
\hline
\end{tabular}

From the weight loss results, it's clear that the corrosion rate of steel in the blank is higher in comparison with the blank containing date extract. The addition of $0.05 \mathrm{~V} / \mathrm{V} \%$ date extract into the aggressive medium reduces this corrosion rate by $54.97 \%$ and reaches $78.07 \%$ at $1.5 \mathrm{~V} / \mathrm{V} \%$. The inhibition efficiency of date extract increase as function of its concentration. This result suggests that an increase in extract concentration increases the number of inhibitor molecules adsorbed onto the steel surface and reduces the surface area that is available for the direct acid attack on the metal surface ${ }^{28}$.

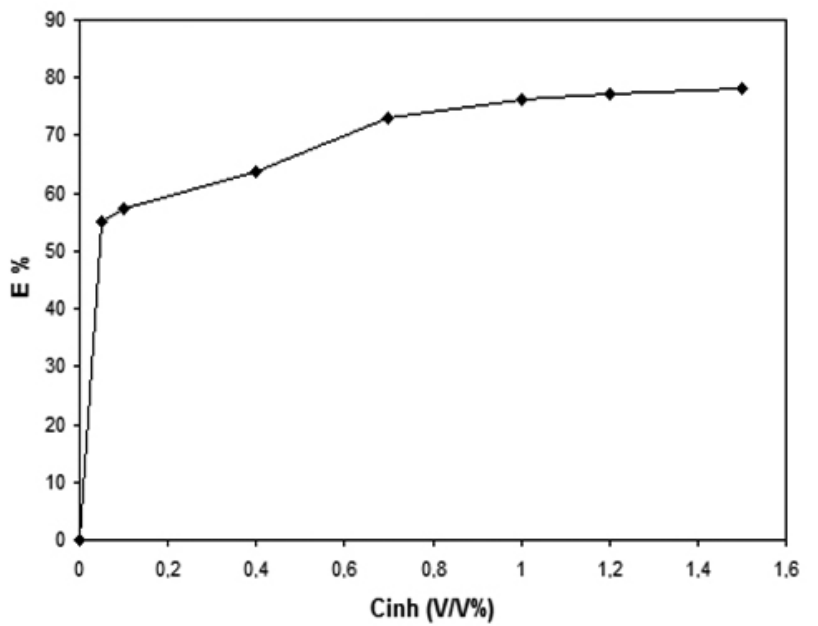

Fig. 1:- Evolution of the inhibition efficiency of carbon steel in $1 \mathrm{M}$ $\mathrm{HCl}$ with various concentrations of date extract. (Obtained from weight loss measurements)

Open circuit potential measurements

Fig. 2 represents the open circuit potential evolution for carbon steel in 1 $\mathrm{M} \mathrm{HCl}$, at room temperature for different concentrations of the date extract $(0$ to $1.5 \mathrm{~V} / \mathrm{V} \%$ ).

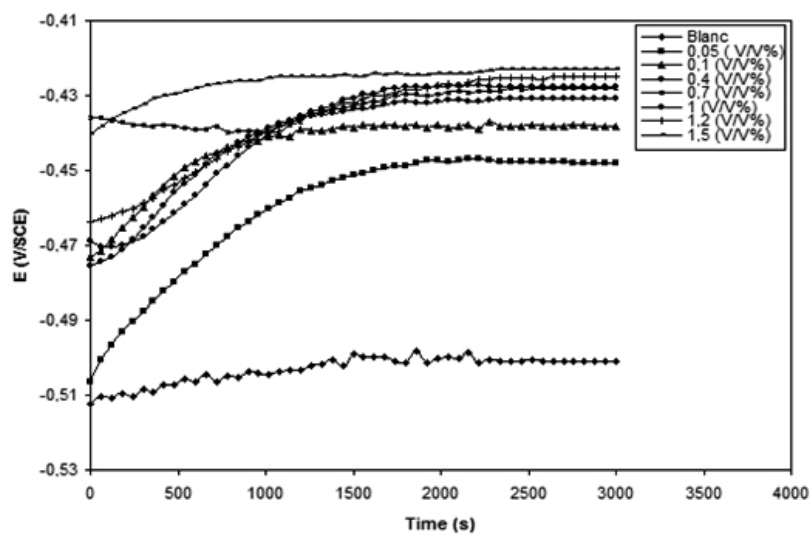

Fig. 2:- Open-circuit potential -time of carbon steel in $1 \mathrm{M} \mathrm{HCl}$ with various concentrations of date extract.

The results showed a change of the open circuit potential in the presence of the date extract.

At $t=0$ potential depends on date extract concentrations, potential shifts to positives values for higher concentrations.

At $t \neq 0$ the potential shifts to the anodic (noble) region indicating the formation of a passive film on the metal surface, and that due to the adsorption of natural compounds on the surface of the metal, for concentration of $1.5 \mathrm{~V} / \mathrm{V} \%$ the potential $E=-0.42$ (V/ECS).

\section{Potentiodynamic polarization measurements}

Fig. 3 shows the Tafel plots of Carbon steel in $1 \mathrm{M} \mathrm{HCl}$ solution containing various concentrations of date extracts at $20^{\circ} \mathrm{C}$. 


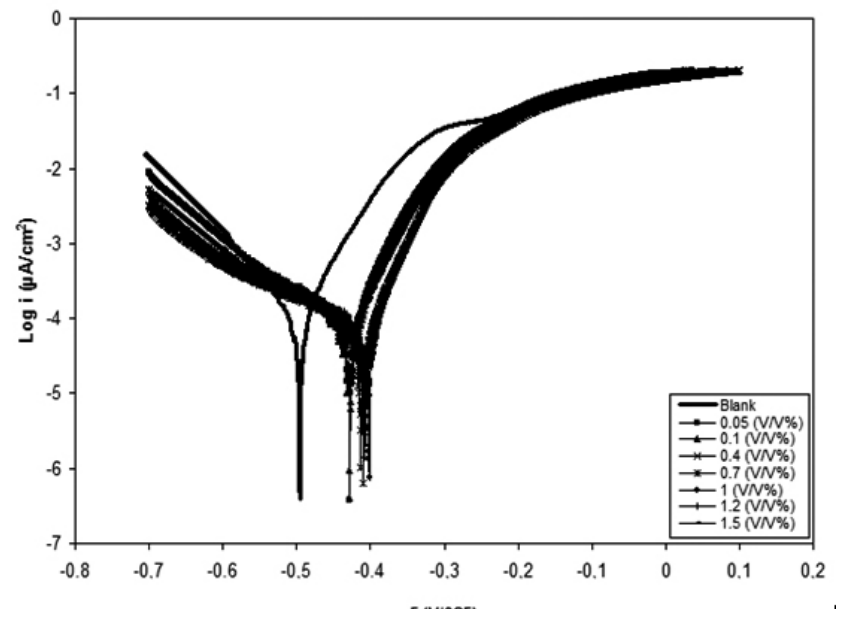

Fig. 3:- Tafel plots of carbon steel in $1 \mathrm{M} \mathrm{HCl}$ solution with various concentrations of date extract.

The corrosion parameters including corrosion current densities $\left(i_{\text {corr }}\right)$, corrosion potential $\left(E_{c o r r}\right)$, cathodic Tafel slope $\left(b_{c}\right)$, anodic Tafel slope $\left(b_{a}\right)$ and inhibition efficiency $(E \%)$ are collected in Table 2 .

Table 2. Electrochemical parameters of carbon steel in $1 \mathrm{M} \mathrm{HCl}$ with various concentrations of date extract at $20^{\circ} \mathrm{C}$.

\begin{tabular}{|c|c|c|c|c|c|c|}
\hline $\begin{array}{c}\text { Concentration } \\
\text { Of date extract }(V / V \%)\end{array}$ & $\begin{array}{c}E_{\text {corr }} \\
(\mathrm{mV} / \mathrm{ECS})\end{array}$ & $\begin{array}{c}b_{c} \\
(\mathrm{mV} / \mathrm{dec})\end{array}$ & $\begin{array}{c}b_{a} \\
(\mathrm{mV} / \mathrm{dec})\end{array}$ & 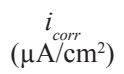 & $\begin{array}{c}E \\
(\%)\end{array}$ & $\theta$ \\
\hline Blank & -495.5 & 130 & 143 & 419.1 & - & - \\
\hline 0.05 & -428.5 & 61 & 152 & 140.34 & 66.51 & 0.6651 \\
\hline 0.1 & -428.5 & 90 & 160 & 119.6 & 71.46 & 0.7146 \\
\hline 0.4 & -410.5 & 87 & 165 & 112.4 & 73.18 & 0.7318 \\
\hline 0.7 & -410 & 76 & 169 & 87.8 & 79.05 & 0.7905 \\
\hline 1 & -401.5 & 85 & 164 & 80.03 & 80.90 & 0.8090 \\
\hline 1.2 & -407.5 & 66 & 179 & 66.91 & 84.03 & 0.8403 \\
\hline 1.5 & -406 & 85 & 172 & 59.31 & 85.84 & 0.8584 \\
\hline
\end{tabular}

From inspection of Table 2 it was found that corrosion current density decreased (from 419.1 to $59.31 \mu \mathrm{A} \mathrm{cm}$ ch $^{-2}$ ) with increasing concentration of inhibitor and attained minimum value for highest concentration used in study, probably due to adsorption of organic compounds from the extracts at the active sites of the electrode surface. This action might have hindered both metallic dissolution and hydrogen evolution reactions, and consequently slowing the corrosion process ${ }^{29,31}$. The decreased current densities were more pronounced with increases in inhibitor concentration, for both extracts. It is also evident from Table 2 that addition of inhibitor shifted corrosion potential Ecorr in anodic direction which indicated that adsorption of inhibitor was more successful at anodic sites than cathodic sites ${ }^{32}$. But Tafel slope values $\mathrm{b}_{\mathrm{a}}$ and $\mathrm{b}_{\mathrm{c}}$ were not with affected significantly in inhibited solution as compared to uninhibited solution. Inhibition efficiency obtained from polarization was found maximum $(85.84 \%)$ at $1.5 \mathrm{~V} / \mathrm{V} \%$ inhibitor concentration.

Electrochemical impendence spectroscopy (S.I.E.)

The electrochemical impedance diagrams for carbon steel immersed in $1 \mathrm{M} \mathrm{HCl}$ solution without and with addition of different concentrations of date extract are shown in fig. 5 .

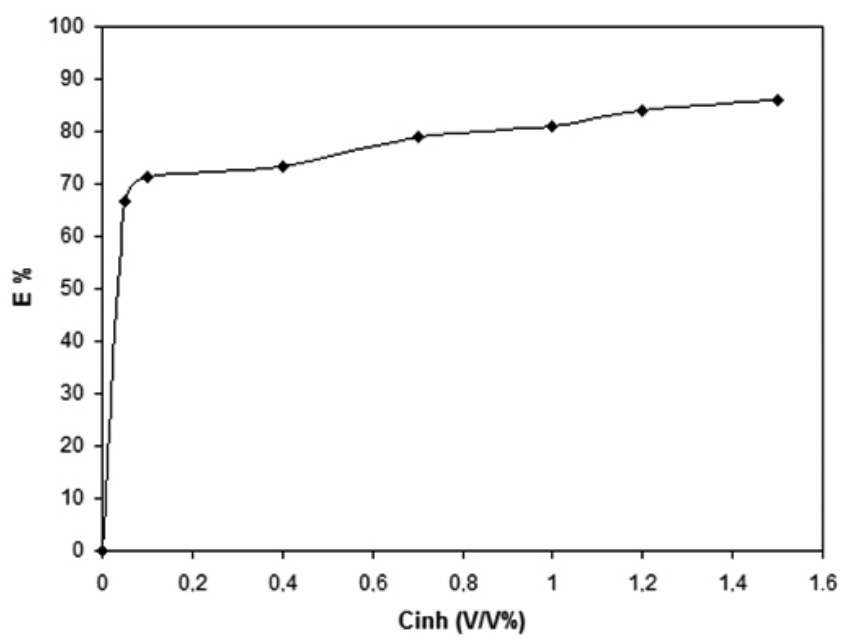

Fig. 4:- Evolution of the inhibition efficiency of steel in $1 \mathrm{M} \mathrm{HCl}$ with various concentrations of date extract (Obtained from Tafel plots). 


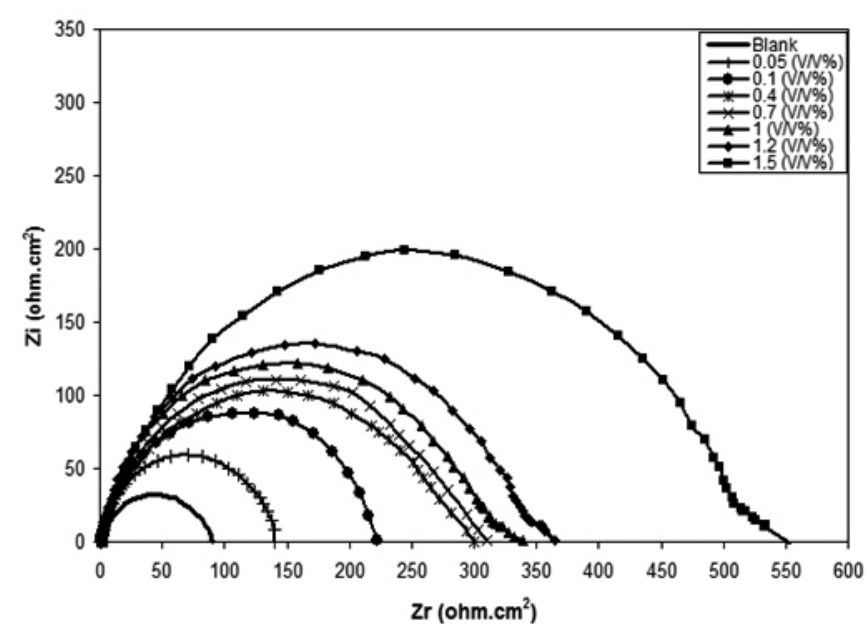

Fig. 5:- Nyquist plots of carbon steel in $1 \mathrm{M} \mathrm{HCl}$ with various concentrations of date extract.

It can be seen from Fig. 5, impedance diagrams show a semi-circular appearance, indicating a charge transfer process mainly controls the corrosion of steel ${ }^{32}$

The electrochemical impedance parameters derived from these investigations are mentioned in Table 3.

Table 3. Electrochemical characteristics of steel in $1 \mathrm{M} \mathrm{HCl}$ with different concentrations of date extract at $20^{\circ} \mathrm{C}$.

\begin{tabular}{|c|c|c|c|}
\hline $\begin{array}{c}\text { Concentration } \\
\text { of date extract } \\
(V / V \%)\end{array}$ & $\begin{array}{c}R_{c t} \\
\left(\Omega . \mathrm{cm}^{2}\right)\end{array}$ & $\begin{array}{c}C_{d l} \\
\left(\mu \mathrm{F} . \mathrm{cm}^{-2}\right)\end{array}$ & $E \%$ \\
\hline Blank & 88.657 & 142.671 & - \\
\hline 0.05 & 139.706 & 71.920 & 36.54 \\
\hline 0.1 & 221.814 & 91.78 & 60.03 \\
\hline 0.4 & 258.794 & 61.829 & 65.74 \\
\hline 0.7 & 310.039 & 51.503 & 71.40 \\
\hline 1 & 339.959 & 49.202 & 73.92 \\
\hline 1.2 & 364.48 & 47 & 75.67 \\
\hline 1.5 & 553.602 & 46.112 & 83.98 \\
\hline
\end{tabular}

From the impedance data, we notice an increase of the charge transfer resistance and decrease of the double layer capacitance with increasing inhibitor concentration. This phenomenon is generally related to the adsorption of organic molecules on the metal surface and then leads to a decrease in the local dielectric constant and/or an increase in the thickness of the electrical double layer indicate that date extract inhibits the corrosion of carbon steel by an adsorption mechanism ${ }^{33}$.

\section{Adsorption isotherms}

Adsorption isotherms are very important to understand the mechanism of inhibition corrosion reactions. The most frequently used isotherms are Langmuir, ${ }^{34}$ Frumkin ${ }^{35}$ and Temkin ${ }^{36}$. The Langmuir isotherm $(C / \theta$ vs $C$ ) assumes that there is no interaction between adsorbed molecules on the surface. The Frumkin adsorption isotherm $(\theta$ vs $C$ ) assumes that there is some interaction between the adsorbates, and the Temkin adsorption isotherm $(\theta$ vs $\lg C)$ represents the effect of multiple layer coverage ${ }^{37}$.

The dependence of the fraction of the surface covered $\theta$ obtained from Tafel extrapolation at $20^{\circ} \mathrm{C}$ as function of date extract concentration $\left(C_{\text {inh }}\right)$ and was graphically fitted for various adsorption isotherms.

Fig. 7 shows the dependence of $\theta$ as function of the logarithm of date extract concentration. The curve obtained clearly shows that the data fit well with Langmuir adsorption isotherm and, it was found to be the best description of the adsorption behavior of the studied inhibitor, which obeys:

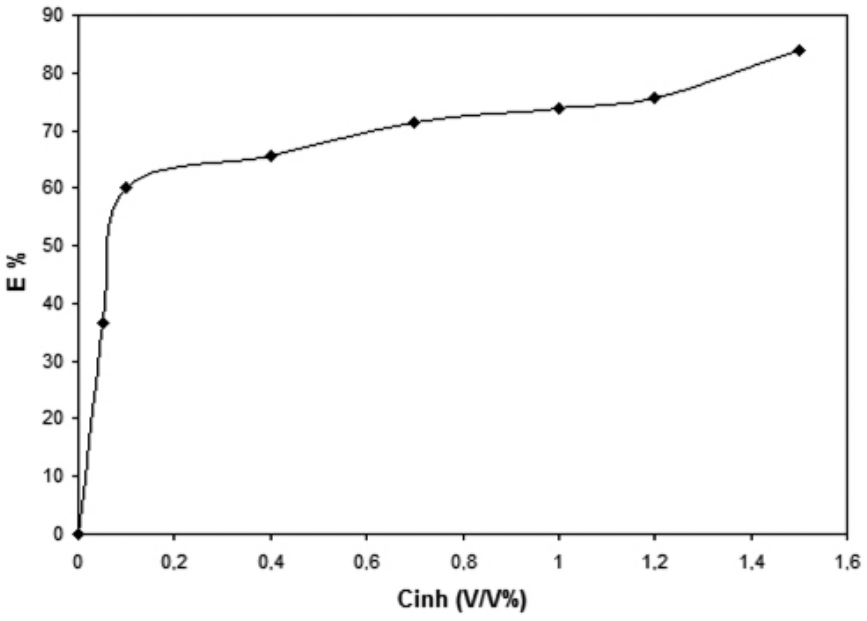

Fig. 6:- Evolution of the inhibition efficiency of steel in $1 \mathrm{M} \mathrm{HCl}$ with various concentrations of date extract. (Obtained from electrochemical impedance diagrams).

$$
\frac{C_{i n h}}{\theta}=\frac{1}{K}+C_{i n h}
$$

$C_{i n h}$ is the inhibitor concentration; $\theta$ is the fraction of the surface covered, $b$ is the adsorption coefficient.

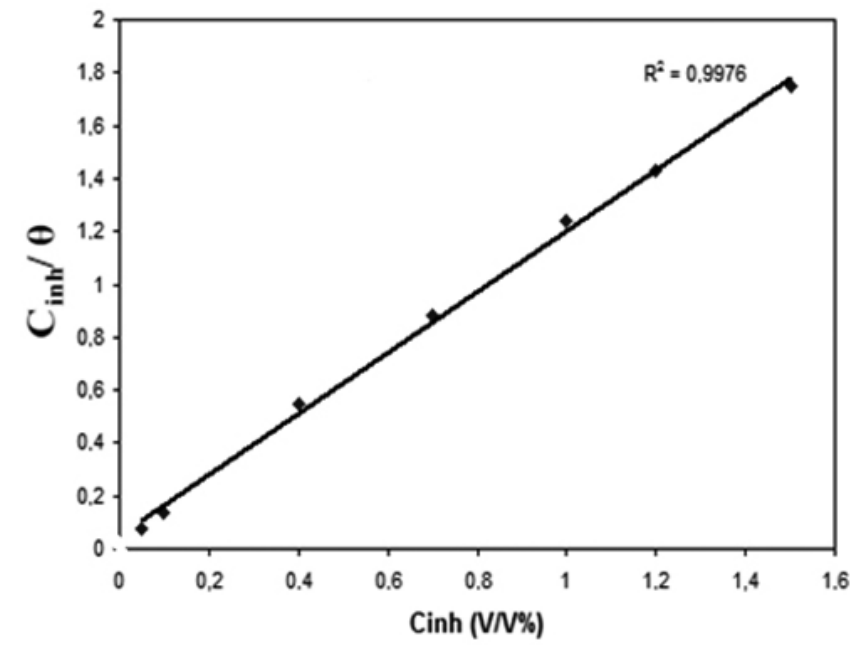

Fig. 7:- Langmuir adsorption isotherm for date extract on carbon steel in $1 \mathrm{M} \mathrm{HCl}$ (Obtained from Tafel extrapolations).

Effect of temperature on corrosion inhibition

The effect of temperature on the corrosion behavior of steel in $1 \mathrm{M} \mathrm{HCl}$ containing inhibitor at a concentration $1.5 \mathrm{~V} / \mathrm{V} \%$ is studied in the temperature range $20-60{ }^{\circ} \mathrm{C}$.

\section{Open circuit potential measurement}

Fig. 8 represents evolution of open circuit potential with time in $1 \mathrm{M} \mathrm{HCl}$ in the presence of $1.5 \mathrm{~V} / \mathrm{V} \%$ of date extract for different temperatures: 20,30 , 40,50 and $60^{\circ} \mathrm{C}$ 


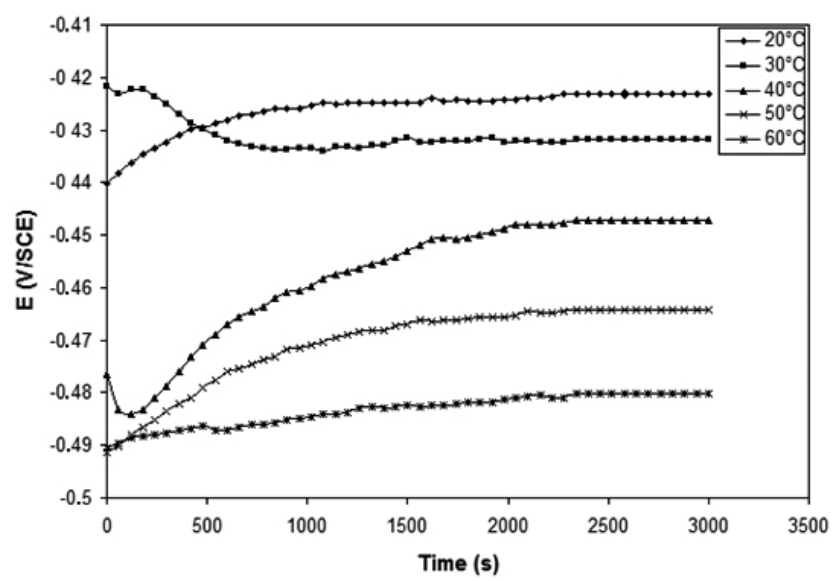

Fig. 8:- Open circuit potential-time of steel in1M HCl with $1.5 \mathrm{~V} / \mathrm{V} \%$ of date extract at different temperatures.

This evolution shows a displacement of the potential to the more negative values with the increase of temperature indicating the desorption of inhibitor.

Potentiodynamic polarization measurement

The effect of the temperature on the different corrosion parameters $E_{\text {cort }}, i_{\text {corr }}$ and $E(\%)$ was studied in $1 \mathrm{M} \mathrm{HCl}$ at temperature ranging from 20 to $60{ }^{\circ} \mathrm{C}$ and for $1.5 \mathrm{~V} / \mathrm{V} \%$ of date extract (Fig. 9).

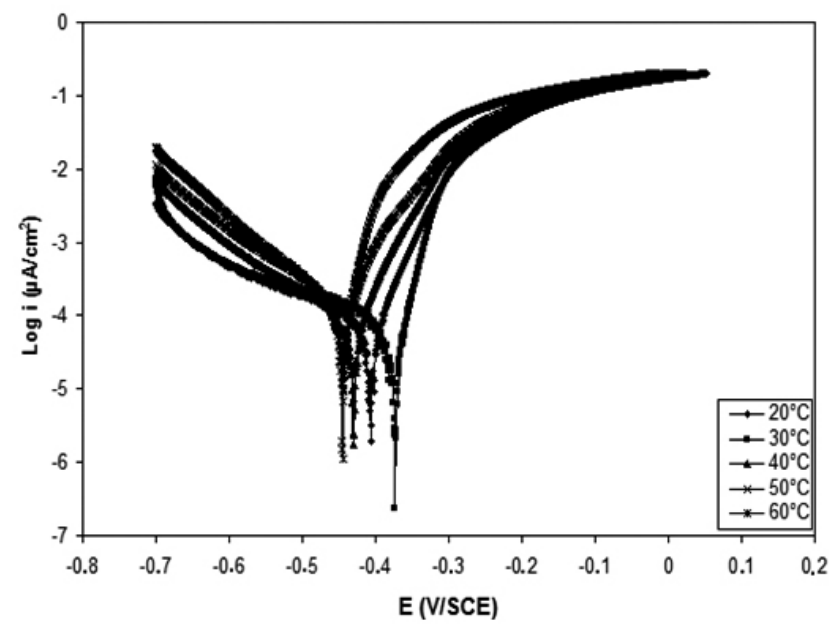

Fig. 9:- Tafel plots of carbon steel in $1 \mathrm{M} \mathrm{HCl}$ with $1.5 \mathrm{~V} / \mathrm{V} \%$ of date extract at different temperatures.

The values of associated electrochemical parameters are given in Table 4 .

Table 4. Electrochemical characteristics of carbon steel in $1 \mathrm{M} \mathrm{HCl}$ with $1.5 \mathrm{~V} / \mathrm{V} \%$ of date extract at different temperatures.

\begin{tabular}{|c|c|c|c|c|c|}
\hline Temperature $\left(C^{\circ}\right)$ & $\begin{array}{c}E_{\text {corr }} \\
(\mathrm{mV} / \mathrm{ECS})\end{array}$ & $\begin{array}{c}b_{c} \\
(\mathrm{mV} / \mathrm{dec})\end{array}$ & $\begin{array}{c}b_{a} \\
(\mathrm{mV} / \mathrm{dec})\end{array}$ & $\begin{array}{c}i_{\text {corr }} \\
\left(\mu \mathrm{A} / \mathrm{cm}^{2}\right)\end{array}$ & $E^{2}$ \\
\hline 20 & -406 & 85 & 172 & 59.31 & 85.84 \\
\hline 30 & -373.074 & 51.927 & 189.669 & 96.63 & 82.86 \\
\hline 40 & -430.873 & 74.052 & 178.758 & 201.03 & 75.18 \\
\hline 50 & -446.189 & 75 & 138.611 & 333.22 & 70.64 \\
\hline 60 & -444.481 & 70.534 & 158.667 & 465.46 & 64.29 \\
\hline
\end{tabular}

It is seen from table 4 that, as the temperature increase, corrosion current density increase.

Inhibition efficiency of this date extract decrease with the increase in the temperature from $85.84 \%$ at $20^{\circ} \mathrm{C}$ to $64.29 \%$ at $60^{\circ} \mathrm{C}$ This phenomenon is due to the desorption of the some molecules from the carbon steel surface by increasing the temperature ${ }^{38}$. 


\section{Electrochemical impendence spectroscopy measurements (S.I.E.)}

The Nyquist representation of the impedance behaviour of carbon steel immersed in $1 \mathrm{M} \mathrm{HCl}$ solution in the presence of $1.5 \mathrm{~V} / \mathrm{V} \%$ of date extract at different temperatures is represented in fig. 10.

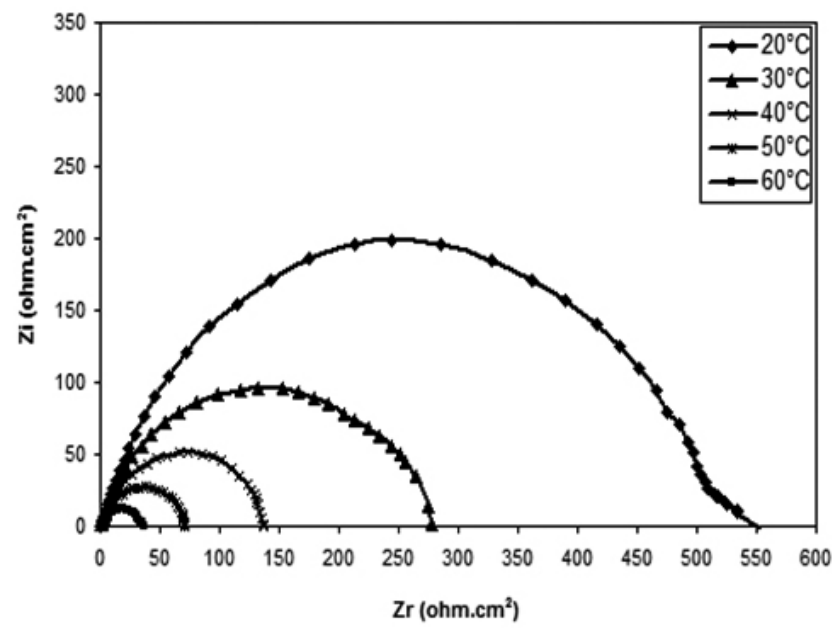

Fig. 10:- Nyquist plots of carbon steel in $\mathrm{HCl}(1 \mathrm{M})$ with $1.5 \mathrm{~V} / \mathrm{V} \%$ of date extract at different temperatures. plots.

Table 5 gives the electrochemical characterization calculated from Nyquist

Table 5. Electrochemical characteristics of steel in $1 \mathrm{M} \mathrm{HCl}$ with $1.5 \mathrm{~V} / \mathrm{V} \%$ of date extract at different temperatures.

\begin{tabular}{|c|c|c|c|}
\hline $\begin{array}{c}\text { Temperature } \\
\left(C^{\circ}\right)\end{array}$ & $\begin{array}{c}R_{c t} \\
\left(\Omega . \mathrm{cm}^{2}\right)\end{array}$ & $\begin{array}{c}C_{d l} \\
\left(\mu \mathrm{F} . \mathrm{cm}^{-2}\right)\end{array}$ & $E \%$ \\
\hline 20 & 553.602 & 46.112 & 83.98 \\
\hline 30 & 277.366 & 90.996 & 80.40 \\
\hline 40 & 135.191 & 107.514 & 72.68 \\
\hline 50 & 67.907 & 117.785 & 70.14 \\
\hline 60 & 34.619 & 145.815 & 65.53 \\
\hline
\end{tabular}

Examination of Table 5 revealed that, as the temperature increased, the values of $C_{d l}$ increase. Also, the temperature rise leads to a decrease of $R_{c t}$ values. This is due on one hand to the increase of the rate of metal dissolution, and on the other hand to the shift of the adsorption/desorption equilibrium towards the extract's desorption and hence to the decrease of surface coverage degree. The values of inhibition efficiency decrease with temperature increase 39 .

\section{Surface examination}

SEM micrograms of polished surface of carbon steel without immersion and exposed for 24 hours in $1 \mathrm{M} \mathrm{HCl}$ solutions in absence and presence of 1.5 $\mathrm{V} / \mathrm{V} \%$ of date extract were shown in figure 11(a)-(c). In comparison of SEM micrograms in absence and presence of the extract, there was a rough surface on carbon steel in absence of the extract. There was a smooth surface with deposited extract on it in presence of the extract ${ }^{40}$. This result supplements the results of electrochemical techniques and confirms that the date extract inhibited corrosion of carbon steel through adsorption of the inhibitor molecules on metal surface.

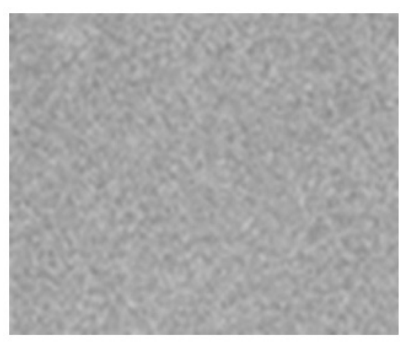

(a)

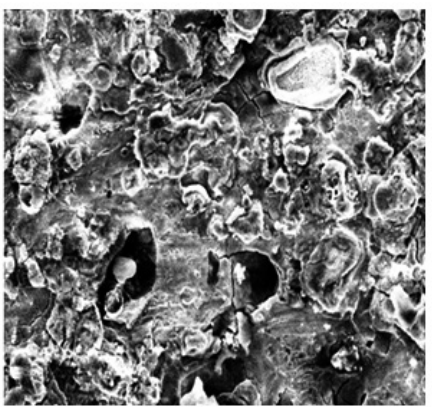

(b)

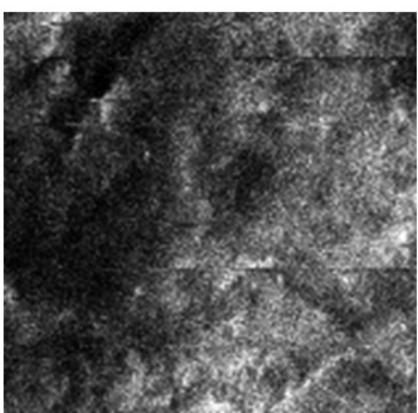

(c)
Fig. 11:-SEM (x1000) of carbon steel (a) before immersion (b) after 24 hours of immersion in $1 \mathrm{M} \mathrm{HCl}$ (c) after 24 hours of immersion in $1 \mathrm{M} \mathrm{HCl}+$ $1.5 \mathrm{~V} / \mathrm{V} \%$ of date extract.

\section{CONCLUSIONS}

Carbon steel corrosion in acid was found considerably retarded in presence of date extract. Results obtained by various techniques were in good connection and maximum efficiency of $85 \%$ was acknowledged for highest inhibitor concentration used in the study, the open circuit potential-times studies showed that dates extract acts as an anodic-type, Electrochemical polarization study and impedance spectroscopy showed that the inhibition efficiency of carbon steel in $1 \mathrm{M} \mathrm{HCl}$ increased with increasing the concentration of the date extract and decreases with increasing temperature. The inhibition efficiency obtained via electrochemical measurements is in good agreement with that obtained by using the weight loss method. The adsorption of the inhibitor on the mild steel surface in $\mathrm{HCl}$ medium obeys Langmuir's adsorption isotherm. SEM examination of the electrode surface confirmed the existence of such adsorbed film.

\section{REFERENCES}

1. Li. X, Deng. S, Fu. H, Li. T, Electrochim. Acta, 54, 4089, (2009)

2. Vračar. L.M, and Dražić. D.M, Corros. Sci, 44, 1669, (2002)

3. Behpour. M, Ghoreishi. S.M, Soltani. N, Salavati-Niasari. M, Corros. Sci, 51, 1073, (2009)

4. Tang. Y.M, Yang. X.Y, Yang. W.Z, Wan. R, Chen. Y.Z, and Yin. X.S, Corros. Sci, 52 , 1801, (2010)

5. Pavithra. M.K, Venkatesha. T.V, Punith Kumar. M.K, and Tondan. H.C, Corros. Sci, 60, 104, (2012)

6. Cang. H, Fei. Z.H, Shao. J.L, Shi. W.Y, and Xu. Q, Int. J. Electrochem. Sci, 8, 720, (2013)

7. Chaieb. E, Bouyanzer. A, Hammouti. B, Berrabah. M, Acta Phys. Chim. Sin, 25, 1254, (2009)

8. El Hosary. A.A, Saleh. R.M, and Shams El Din. A.M, Corros. Sci, 12, 897, (1972)

9. Ekpe. U.J, Ebenso. E.E, Ibok. U.J, J. West African Assoc, 37, 13, (1994)

10. Loto. C.A, Nig. Cor. J, 19, 20, (1998)

11. Chetouani. A, and Hammouti. B, Bull. Electrochem, 19, 23,(2003)

12. Orubite. K.O, and Oforka. N.C, Mater. Lett, 58, 1768, (2004)

13. Sharma. S.K, Mudhoo. A, Jain. G, and Sharma. J, Green Chem. Lett. Rev, 3, 7, (2010)

14. Sivaraju. M, and Kannan. K, Int. J. Chem. Tech. Res, 2, 1243, (2010)

15. Chuanhan. L.R, and Gunasekaran. G, Corros. Sci, 49, 1143, (2007) 
16. Abdel-Gaber. A.M, Abd-El Nabey. B.A, Sidahmed. I.M, El-Zayady. A.M, and Saadawy. M, Corrosion, 62, 293, (2006)

17. Eddy. N.O, Port. Electrochim. Acta, 27, 579, (2009)

18. Quraishi. M.A, ngh. Si.A, Singh. V.K, Yadav. D.K, and Singh. A.S, Mater. Chem. Phys, 122, 114, (2010)

19. Satapathy. A.K, Gunasekaran. G, Sahoo. S.C, Amit. K, and Rodrigues. R.V, Corros. Sci, 51, 2848, (2009)

20. Lebrini.M, Robert. F, Lecante. A, and Roos. C, Corros. Sci, 53, 687, (2011)

21. Deng. S.D, X. and Li. H, Corros. Sci, 55, 407, (2012)

22. Cang. H, Shi. W.Y, Shao. J.L, and Xu. Q, Int. J. Electrochem. Sci, 7, 3726, (2012)

23. Ashassi-Sorkhabi. H, Seifzadeh. D, Int. J. Electrochem. Sci, 1, 92, (2006)

24. Chetouani. A, Hammouti. B, Benkaddourm. M, Pigm. Resin Technol, 33, 26, (2004)

25. Znini. M, Majidi. L, Bouyanzer. A, Paolini. J, Desjobert. J.M, Costa. J, Hammouti. B, Arabian. J. Chemistry, 5, 467, (2012)

26. Raja. P.B, Sethuraman. G, Materials Letters, 62, 2977, (2008)

27. Kalaiselvi. P, Chellammal. S, Palanichamy. S, Subramanian. G, Materials Chemistry and Physics, 120, 643, (2010)

28. Khadraoui. A, Khelifa. A, Hamitouche. H, Mehdaoui. R, Res. Chem.
Intermed, 40, 961, (2014)

29. Da Rocha. J.C, Gums. J A. C, D’ Elia. E, Corrosion Science, 52, 2341, (2010)

30. EL-ETRE. A.Y, Corrosion Science, 40, 1845, (1998)

31. J. C. da Rocha, J. A. C. Ponciano Gomes, E. D’Elia, A. P. Gil Cruz, L. M. C. Cabral, A. G. Torres, M. V. C. Monteiro, Int. J. Electrochem. Sci. 7, 11941 (2012)

32. A. Khadraoui, A. Khelifa, H. Boutoumi, H. Hamitouche, R. Mehdaoui, B. Hammouti, S.S. Al-Deyab, Int. J. Electrochem. Sci. 9, 3334 (2014)

33. E.E. Oguzie, C.K. Enenebeaku, C.O. Akalezi, S.C. Okoro, A.A. Ayuk, E.N. Ejike, J.Coll.Interf. Sci. 349, 283 (2010)

34. Langmuir. I, J. Am. Chem. Soc, 39, 184, (1947)

35. Frumkin. A.N.Z, Phys. Chem, 116, 466, (1925)

36. de Boer. J.H, The Dynamical Character of Adsorption, second ed. Claredon Press, Oxford, UK, 1968.

37. Masel. R.I, Principles of Adsorption and Reaction on Solid Surfaces. Willey, New York, 1996.

38. Belkhaouda. M, Bammou. L, Salghi. R, Zarrouk. A, Ebenso. Eno. E, Zarrok. H, Hammouti. B, Int. J. Electrochem. Sci, 8, 10999, (2013)

39. Lebrini.M, Robert. F, Roos. C, Corros.Sci, 5, 1698, (2010).

40. M. Ramananda Singh, J. Mater. Environ. Sci, 4, 119, (2013) 